\title{
A Comparison of Chewing Movements of Individuals with Normal Occlusion by the Patients with Orthodontic Abnormalities During Treatment Progress
}

\author{
Normal Oklüzyonlu Bireylerle Ortodontik Anomali Tedavisi Gören \\ Hastaların Çiğneme Hareketlerinin Kıyaslanması
}

\author{
(1) Bilgin Giray
}

İstanbul Aydın University Faculty of Dentistry, Department of Orthodontic, İstanbul, Turkey

Keywords

Masticatory movements, orthodontic

treatment, dental occlusion

Anahtar Kelimeler

Çiğneme, ortodonti, oklüzyon

Received/Geliş Tarihi : 03.05.2018

Accepted/Kabul Tarihi : 18.06.2018

doi:10.4274/meandros.galenos.2018.04127

Address for Correspondence/Yazışma Adresi: Bilgin Giray MD,

İstanbul Aydın University Faculty of Dentistry, Department of Orthodontic, İstanbul, Turkey

Phone : +90 5322313489

E-mail : giray.bilgin@gmail.com

ORCID ID: orcid.org/0000-0002-2344-2798

(C) Meandros Medical and Dental Journal, Published by Galenos Publishing House.

This is article distributed under the terms of the

Creative Commons Attribution NonCommercial 4.0

International Licence (CC BY-NC 4.0).

\begin{abstract}
Objective: Comparison of chewing movements of individuals with normal occlusion and those with orthodontic anomalies under treatment.

Materials and Methods: This is a prospective clinical study carried out on a total of 63 individuals, including 43 patients with malocclusion and an average age of 16.79 years, whose growth and development were partially complete and 20 individuals with normal occlusion and an average age of 24.77 years. Subjects with normal occlusion have not any orthodontic treatment history.

Results: There were significant differences in chewing occlusion times $(p<0.05)$ and opening and closing times $(\mathrm{p}<0.01)$. Furthermore, significant differences were also found in modification results of class $1(p<0.05)$ and class $2(p<0.01)$ malocclusions. Conclusion: Repositioning of the teeth in chewing movements obtained at the onset of orthodontic treatments tends to change within the end of the 6-month period from the onset of the treatment in individuals with malocclusion.
\end{abstract}

Öz

Amaç: Normal oklüzyonlu ve tedavi altındaki ortodontik anomalili bireylerin çiğneme hareketlerinin karşılaştırılması.

Gereç ve Yöntemler: Bu çalışma, maloklüzyonlu 43 hasta ve ortalama yaşları 16,79 yıl olmak üzere, büyüme ve gelişmesi kısmen tamamlanmış, 20'si normal oklüzyonlu ve yaş ortalaması 24,77 yıl olan toplam 63 birey üzerinde yapılan prospektif bir klinik çalışmadır.

Bulgular: Oklüzyon süresinde $(p<0,05)$ ve açılma ve kapanma oranlarında anlamlı fark bulundu $(p<0,01)$. Ayrıca, sınıf $1(p<0,05)$ ve sınıf $2(p<0,01)$ malokluzyonların modifikasyon sonuçlarında da anlamlı farklılıklar bulunmuştur.

Sonuç: Ortodontik tedavinin başlangıcında elde edilen çiğneme hareketlerinde dişlerin yeniden konumlandırılması, maloklüzyonlu bireylerde tedavinin başlangıcından itibaren altı aylık sürenin sonunda değişme eğilimindedir. 


\section{Introduction}

Studies on mastication physiology and chewing patterns have a long history in dentistry. However, it has been observed that less studies were conducted on effect of chewing performance on malocclusion in the literature (1). Furthermore, there is no study found which compares the chewing patterns of young individuals with malocclusion who are about to complete normal occlusion development. Hypothetically, changes in chewing characteristics must be expected within the 6-month period from the onset of the treatment procedure because of changing of tooth movement. In this study chewing performance is measured and benchmarked before and after the study by using a jaw tracker device.

In the literature view, the following methods are commonly used in the studies investigating the chewing function (2): a-Analysis of chewing movements, b-Analysis of chewing muscle activity (Electromyography studies) (3-6) or c-Analysis of chewing process results (analysis of the status just after chewing and before swallowing a food particle) $(1,7)$. Efficiency of restorations, the status before orthodontic studies, chewing analyses during and after the treatment process may provide important information about treatment process and outcomes (8). Thomas et al. (1) obtained the findings indicating that orthodontic treatment process may recover motor functions such as chewing in a pilot study conducted on 15 individuals.

No study has been found that focuses on the change of chewing patterns in the groups with orthodontic malocclusion on the individuals with class 1 occlusion and on the control group in the literature (9).

The chewing pattern is a periodical and functional movement style and aims to break down, mesh and prepare the food for digestion. All receptors in the system are enabled to create such function (3). A central pattern generator and associated motor neurons control strength, form, opening and closing durations and occlusion durations of biting forces and prevent damage of the organs in peripheral nervous system $(10,11)$.

In a manuscript published by Hill (2), chewing cycle has three main components as follows; opening time (OT), closing time (CT) and occlusal time (OcT). Normal cycle duration varies between 600 and 900 miliseconds and each phase is roughly $1 / 3$ of total chewing cycle. The OcT is slightly less than $1 / 3$ of total chewing time. Record of chewing movements are observed at three planes as frontal, sagittal and horizontal. The most commonly used material used for chewing movements is the gum. Pattern of the chewing movement also depends on the food. Opening phase and closing phase were detected as $225 \pm 25 \mathrm{msec}$ whereas occlual phase was $200 \pm 25$ msec $(10,12)$. The disoders during occlusal phase of teeth contacts of chewing phase would affect harmonization of the chewing system and cause pathological changes in the joints (13).

Analysis of temporomandibular joint (TMJ) under a load during functioning is important for operation for joint problems. Restructuring and recreation of TMJ with realistic anatomic and kinematic data is the only method providing an in vivo, three dimensional, dynamic and real time quantitative aspect to the relation between articulation surfaces of a joint (14).

It was revealed in a study conducted by Ngom P.I. et al. (15) where chewing efficiency was evaluated on 102 untreated individuals that recovery of chewing functions should be one of indication options as well as aesthetic and other indications for treatment. Yamashita et al. (16) reported in a review that a significant association exists between chewing efficiency and chewing pattern and hardness of the food was suggested to affect the chewing pattern and along with customization of the pattern, count may also be important.

Clark and Evans (17) have determined an ideal orthodontic occlusion frame where one of the basic rules was reported as demonstration of the function. However, Trawitzki et al. (14) could not detect any significant association between maximum isometric chewing strength and class 2 and class 3 dentofacial deformity in their study conducted on 125 volunteer patients. Furthermore, they reported that the values of both (class 2 and class 3 ) study groups were below the values of the control group. Effect of curve of spee on chewing efficiency was also investigated; it was concluded that the idea that a regular curve of Spee may create an efficient chewing is not true $(17,18)$.

Therefore, the investigation of this topic is necessitated. The aim of the present study is to compare chewing patterns of the individuals with skeletally normal occlusion with those who have 
abnormalities during an orthodontic treatment to offer an insight to further studies. In this comparison, differences of possible changes in chewing efficiency, opening and $\mathrm{CT}$, OcT during chewing, vertical opening distance and the distance between opening and closing were analyzed.

\section{Materials and Methods}

The study protocol was approved by the Ethics Committee at the İstanbul Aydın University, Faculty of Dentistry, and written informed consent was obtained from all subjects prior to the study.

The present prospective clinical study was carried out on 63 individuals referred to Department of Orthodontics, Faculty of Dentistry, İstanbul Aydın University for treatment purposes in 2016 including 43 patients with malocclusion and average age of 16.8 years whose growth and development terminated partially and 20 individuals with normal occlusion and average age of 24.8 years who never had any orthodontic treatment before. Healthy individuals who were at permanent dentition period and might tolerate the treatment were also included into the study. The present research was divided into three groups.

1. Group $1 ; 25$ individuals (58\%) class 1 , (8 male + 17 female)

2. Group 2; 18 individuals (41.9\%) class 2, (9 male +9 Female)

3. Control group including 20 class 1 individuals with normal occlusion who were not treated before.

Data collection was performed with the parameters consisting of three main components at two intervals: T0, before the treatment; T1 $6^{\text {th }}$ month after the treatment. A fixed Edgewise Roth technique was applied to the patient for treatment purposes. During first 6-month period of the treatment, 0.22-inch Roth bracket and $0.014 \mathrm{Ni}-\mathrm{Ti}$ arch wires for alignment of lower and upper mandible at the beginning were used; $0.016,0.018$ and $0.016 \times 0.022 \mathrm{Ni}-\mathrm{Ti}$ arch wires were used during the treatment. The following criteria were considered during material collection;

1. Being at the end of pubertal excretion period skeletally,

2. Individuals being at permanent dentition period and eruption of all teeth,

3. Being angle class 1 and class 2 in terms of skeletal and dental molar association clinically and not having premolar and molar tooth loss more than one,
4. For the control group, having skeletal and dental molar and canine teeth with normal occlusion and angle class I and minimum crowding on the anterior zone. The following points are used to exempt patients from the study,

5. Individuals with previously known syndrome, systemic disorder, craniofacial abnormality, cleft lip/ palate,

6. Individuals who had any orthodontic treatment before with removable or fixed apparatus,

7. Individuals with complaint of any periodontal and TMJ disorder,

8. Congenital tooth deficiency except $3^{\text {rd }}$ large grinders.

Approval of İstanbul Aydın University, Medicine and Health Sciences Research Board and Commitee of Ethics were obtained to carry out the research (B.30.2.AYD.0.00.00-480.2/0106, EK-1) (ANNEX-1) 9) All individuals participated into the present research voluntarily and informed consent forms were obtained from all patients and their parents.

The study group ( $n=43$ ) had average age of 16.8 years and Standard deviation of \pm 5.55 whereas the control group $(n=20)$ had average age of 24.8 and Standard deviation of \pm 4.04 .

The study materials consisted of lateral cephalometric and panaromic radiographs taken before and during fixed orthodontic treatment with/ without extraction, intraoral and extraoral digital photos, orthodontic cast models and chewing analysis records (Figure 1).

Lateral cephalometric films of all participants were taken in İstanbul Aydın University, Department of Orthodontics. The anatomic spots and measurements used in the present research were obtained through selection from Steiner analyses. Ten lateral films were selected randomly and radiographs of same patients were drawn subsequently with 1-month interval to minimize the errors of drawing. Method error of each measurement was calculated to detect repeatibility. Measurement recurrence coefficients range between 0.95 and 0.99 .

For the cephalometric points, planes and angles used in the research; point $S$ was marked as Cella; point $\mathrm{N}$ was marked as frontonasal suture; point $\mathrm{A}$ was marked as subspinal and point $B$ was marked as supramental points. Angles SNA, SNB and ANB were created according to Steiner's analysis. 
Evaluation of lateral cephalometric films;

Films with angle ANB between $>0^{\circ}$ and $-<4^{\circ}$ with crowding at lower and upper mandibles were selected as angle class 1 malocclusion group,

1. Films with angle ANB $>4^{\circ}$ was evaluated as skeletal angle class 2 div 1 and selected as class 2 malocclusion group.

2. Films with angle ANB between $>0^{\circ}$ and $-<4^{\circ}$ and individuals with normal occlusion who do not need any treatment were selected as the control group.

The association of chewing movements with occlusion and characteristics of chewing pattern of the present study were obtained by a device called Bio-JT developed by Bioresearch Inc. (Milwaukee, USA) and a chewing analysis sfotware developed by Prof. Maruyama $(13,14)$. For occlusion evaluation of chewing movements in the study, head of the patient was positioned to make the frankfort plane paralel to the ground. The head part was placed to the patient for chewing movement and both sides were made symmetrical and even through right and left screws. The lower horizontal bar was placed; then, a special magnet adhesive which was specifically developed for the device was placed on anterior surface of loweranterior teeth through a wax (Ormco, No.757-0001) and fixed. A gum was given to the participant and the participant was instructed to chew it on the left side. Same chewing movement was instructed to all participants both inthe control and study group and uniformity of the study was provided. After a chewing movement for about 15 to 20 minutes, record was completed and the procedure was ended, the records were kept in the computer for statistical analysis.

Analyses of the present study was performed on 7 parameters obtained through three main components during chewing: 1 . Opening phase, 2. Closing phase, 3. Occlusal phase.

The software "Mastication" which operates as integrated in Biopak program with Bio-JT device was used (14). Chewing velocity was assessed and maximum opening distance during chewing was examined. The following parameters were analyzed through chewing pattern analysis; (1) Chewing OT, (2) Chewing CT, (3) Chewing OcT (4) Cycle Time (cycleT) (mm/sec), (5) Terminal Chewing Position (TCP) Vertical $(\mathrm{mm})$ (vertical TP), (6) Opening Velocity $(\mathrm{mm} / \mathrm{sec}),(7)$ Closing Velocity $(\mathrm{mm} / \mathrm{sec})$.

\section{Statistical Analysis}

Evaluation of all following findings provide data of chewing efficiency of the individuals in the study group without any orthodontic abnormality and the individuals with malocclusion. The statistical analysis performed with chewing analysis findings: Power and sample size calculation (Version: 3. 1. 2, Copyright 2017, Informer Technologies, Inc., New York, USA) software was used for selection of the individuals and creation of the groups. Although working with equal sample sizes are highly desired, the present study was carried out on the groups with equal unit sample counts and different unit sample counts. The study was started with 90 individuals and this sample count was reduced to 63 by considering the inclusion criteria. The strength of the test was accepted as $80 \%$ and significance level as $(p<0.05)$ for hypotheses to be established on at least 13 patients ( 13 and 43 patients each in both groups) through sample calculation program (19).

All statistical analyses performed on the data base were done through SPSS software (IBM SPSS Statistics Version 19-22, New York, USA). Averages and standard deviations of all samples were calculated by this software. In consideration of equal sample counts $\left(n=n_{1}=n_{2}\right)$ and different sample counts, "paired sample t-test" and nonparametric Wilcoxon test were used to compare two dependent group averages, and Mann-Whitney $U$ test was utilized for comparison of two independent group averages. The $p$ values of $(p<0.05)$ and $(p<0.01)$ were accepted as significant, respectively for the hypotheses to compare the differences between averages of the variables in both groups (20).

\section{Results}

In the present study, findings of the individuals who completed their development during the 6-month period of the treatment may be reviewed under three phases the first phase is the comparison of the statistical changes and the control of the importance to detect the differences between the control group and the group with initial malocclusion. Table 1 presents the comparison of the control group and malocclusion group under seven parameters, the values of the control group is lower than OcclTO and CycleTO changes and this was not statisically significant. The СТО parameter was found higher, which 
was not statistically significant. The measurement values of the other five parameters were found higher, and statistically significant changes are in question $(p<0.01)$. The distribution of the variables of malocclusions according to the groups was provided in Figure 2.

Table 2 presents the association between initial values of the abnormality group and changes after the first 6-month treatment. Among such variables, OpenT0 $(p<0.05)$ increased, and such increase is statistically significant. The increase at CTO, vertical TCP, Average opening velocity and Average closing velocity $(p<0.01)$ levels is statistically significant. Furthermore, OcclT0 $(p<0.05)$ decreased by treatment, and this was also found as statistically significant. Although

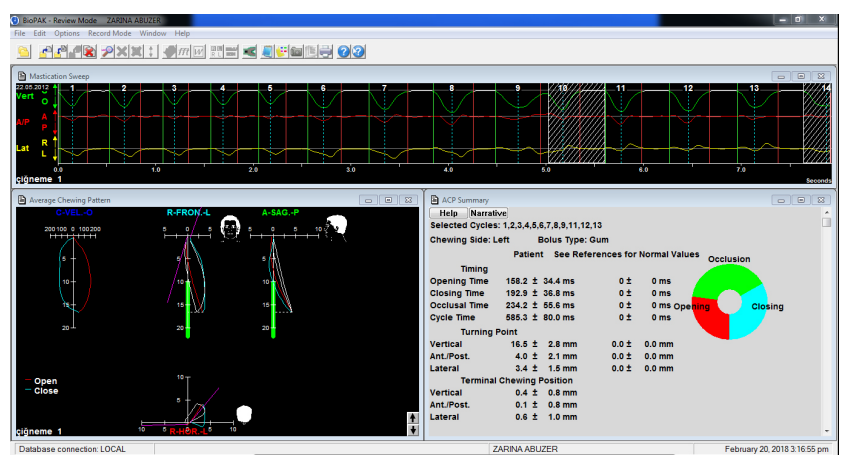

Figure 1. Evaluation of chewing patterns with JT the variable CycleTO decreased by the treatment, such decrease was not statistically significant. Figure 3 provides the averages of the variables observed at the beginning and the end of the 6-month period.

Initial values of the individuals with class 1 and class 2 malocclusion were compared with the changes after 6-months through comparison of averages of two independent groups.

It was detected that class 1 and class 2 values of 6 variables increased by treatment and OcclTO class 2 variable decreased; however, these were not found statistically significant.

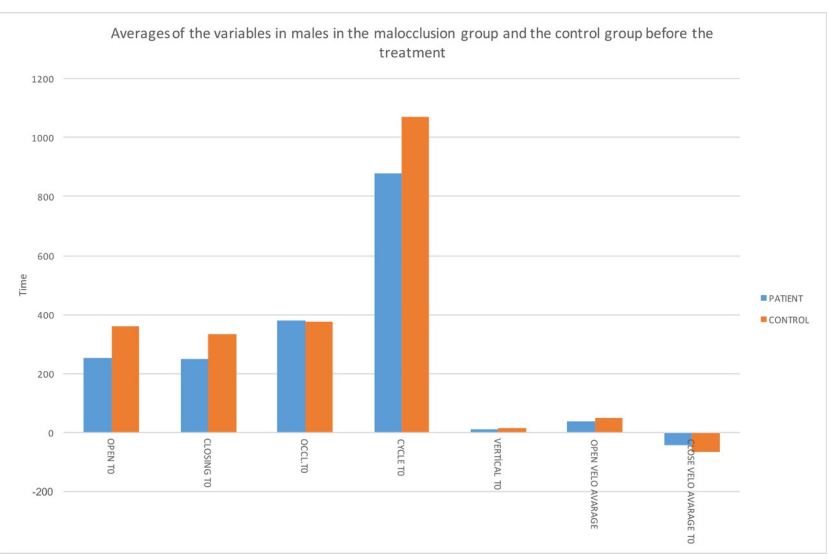

Figure 2. Averages of the variables of malocclusions before the treatment (TO: Control values) according to TO group

Table 1. Averages of malocclusions before the treatment according to time 0 ; comparison with the control group and control of importance

\begin{tabular}{|c|c|c|c|c|c|c|}
\hline Parameters & Mean & $n$ & SD & SE & p & \\
\hline Open time 0 (initial) & 271.08 & 43 & 77.08 & 11.75 & 0.008 & $* *$ \\
\hline Open time 0 (control) & 338.19 & 20 & 78.93 & 21.89 & & \\
\hline Closing time 0 (initial) & 258.66 & 43 & 50.08 & 7.67 & 0.006 & $* *$ \\
\hline Closing time 0 (control) & 315.42 & 20 & 94.20 & 26.13 & & \\
\hline Occlusal time 0 (initial) & 384.07 & 43 & 173.11 & 26.40 & 0.786 & NS \\
\hline Occlusal time 0 (control) & 370.13 & 20 & 112.24 & 31.24 & & \\
\hline Cycle time 0 (initial) & 864.965 & 43 & 277.12 & 42.26 & 0.773 & NS \\
\hline Cycle time 0 (control) & 837.04 & 20 & 383.12 & 106.26 & & \\
\hline Vertical TCP TO (initial) & 9.00 & 43 & 3.09 & 0.47 & 0 & $* *$ \\
\hline Vertical TCP TO (control) & 15.71 & 20 & 4.4 & 1.22 & & \\
\hline Avarage open velo time 0 (initial) & 34.54 & 43 & 14.64 & 2.23 & 0.001 & $* *$ \\
\hline Average open velo time 0 (control) & 51.45 & 20 & 13.72 & 3.80 & & \\
\hline Avarage close velo time 0 (initial) & -37.84 & 43 & 16.39 & 2.50 & 0.000 & $* *$ \\
\hline Average close velo time 0 (control) & -60.85 & 20 & 14.35 & 3.98 & & \\
\hline
\end{tabular}


Table 3 compares the changes of class 1 and class 2 malocclusion during at the and of the 6-month treatment period. Analyses of the dependent ingroup averages of abnormalities were performed with paired t-test and Wilcoxon test. CycleT0 class 1 , class 2 parameters and OpenT0 class 1 were not found as statistically signifcant. The other parameters showed changes with the treatment and statistically significant changes appeared after the treatment, $(p<0.05)$ and $(p<0.01)$. Table 4 includes the cephaloetric measurements.

Table 2. Changes of abnormalities and initial variables within 6-month treatment period and control of the associations

\begin{tabular}{|c|c|c|c|c|c|c|}
\hline Parameters & Mean & $\mathbf{n}$ & SD & SE & p & \\
\hline Open T0 (initial) & 271.08 & 43 & 77.08 & 11.75 & 0.024 & $*$ \\
\hline T1 (Treatment $6^{\text {th }}$ Month) & 307.70 & 43 & 74.83 & 11.41 & & \\
\hline Closing T0 (initial) & 258.66 & 43 & 50.08 & 7.64 & 0.002 & $* *$ \\
\hline T1 (Treatment $6^{\text {th }}$ Month) & 302.58 & 43 & 78.54 & 11.98 & & \\
\hline Occlusal TO (initial) & 384.07 & 43 & 173.11 & 26.34 & 0.023 & $*$ \\
\hline T1 (Treatment $6^{\text {th }}$ Month) & 312.44 & 43 & 91.27 & 13.92 & & \\
\hline Cycle TO (initial) & 864.96 & 43 & 277.12 & 42.26 & 0.626 & NS \\
\hline T1 (Treatment $6^{\text {th }}$ Month) & 844.06 & 43 & 246.99 & 37.67 & & \\
\hline TCP vertical TO (initial) & 9.00 & 43 & 3.10 & 0.47 & 0.000 & $* *$ \\
\hline T1 (Treatment $6^{\text {th }}$ Month) & 14.56 & 43 & 4.18 & 0.64 & & \\
\hline Avarage open velo (initial) & 34.58 & 43 & 14.64 & 2.23 & 0.000 & $* *$ \\
\hline T1 (Treatment $6^{\text {th }}$ Month) & 54.13 & 43 & 16.11 & 2.46 & & \\
\hline Avarage close velo (initial) & -37.4 & 43 & 16.39 & 2.50 & 0.000 & $* *$ \\
\hline T1 (Treatment $6^{\text {th }}$ Month) & -59.79 & & 19.15 & 2.92 & & \\
\hline
\end{tabular}

\section{Table 3. Comparison of dependent in-group averages of the abnormalities}

\begin{tabular}{|c|c|c|c|c|c|c|}
\hline Parameters & $\mathbf{n}$ & Mean & SD & SE & p & \\
\hline Open T0-T1 & 25 & 280.52 & 76.67 & 15.34 & 0.242 & NS \\
\hline Open T0-T1 & 18 & 257.96 & 77.86 & 18.35 & 0.046 & $*$ \\
\hline Closing T0-T1 & 25 & 303.84 & 69.93 & 13.99 & 0.006 & $* *$ \\
\hline Closing T0-T1 & 18 & 313.06 & 82.92 & 19.54 & .0 .050 & $*$ \\
\hline Occlusal T0-T1 & 25 & 253.94 & 50.38 & 10.07 & 0.021 & $*$ \\
\hline Occlusal T0-T1 & 18 & 265.22 & 50.34 & 11.86 & 0.270 & NS \\
\hline Cycle T0-T1 & 25 & 287.63 & 54.20 & 10.84 & 0.307 & NS \\
\hline Cycle T0-T1 & 18 & 323.35 & 101.53 & 23.93 & 0.778 & NS \\
\hline TCP Vertical T0-T1 & 25 & 370.57 & 155.08 & 31.01 & 0.000 & $* *$ \\
\hline TCP Vertical T0-T1 & 18 & 402.81 & 198.61 & 46.81 & 0.000 & $* *$ \\
\hline Open velo T0-T1 & 25 & 53.35 & 12.85 & 2.57 & 0.000 & $* *$ \\
\hline Open velo T0-T1 & 18 & 55.22 & 20.15 & 4.75 & 0.002 & $* *$ \\
\hline Close velo T0-T1 & 25 & -37.01 & 13.26 & 2.65 & 0.000 & $* *$ \\
\hline Close velo T0-T1 & 18 & -38.98 & 20.33 & 4.79 & 0.004 & $* *$ \\
\hline
\end{tabular}


Intergroup tests were conducted among the anomalies of the variables during the treatment period. Statistically significant changes did not occur.

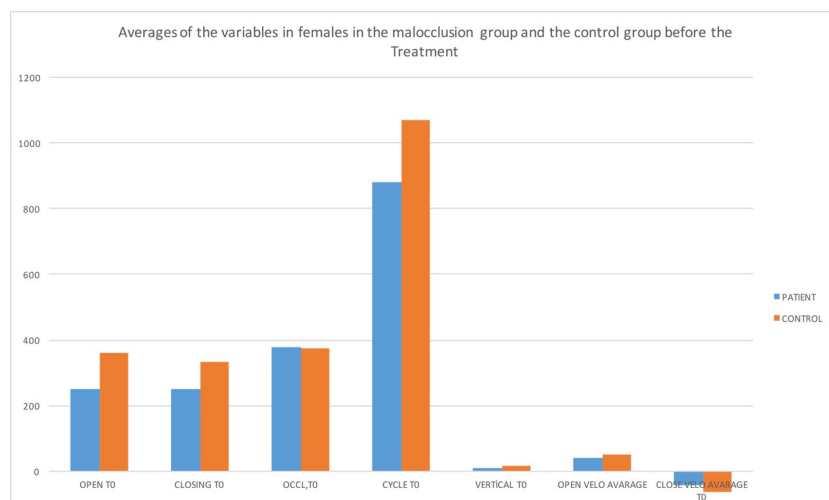

Figure 3. Averages of the variables at the beginning and the end of the 6-month period
Figure 4 demonstrates the average differences between initial and 6-months treatment values of class 1 and class 2 .

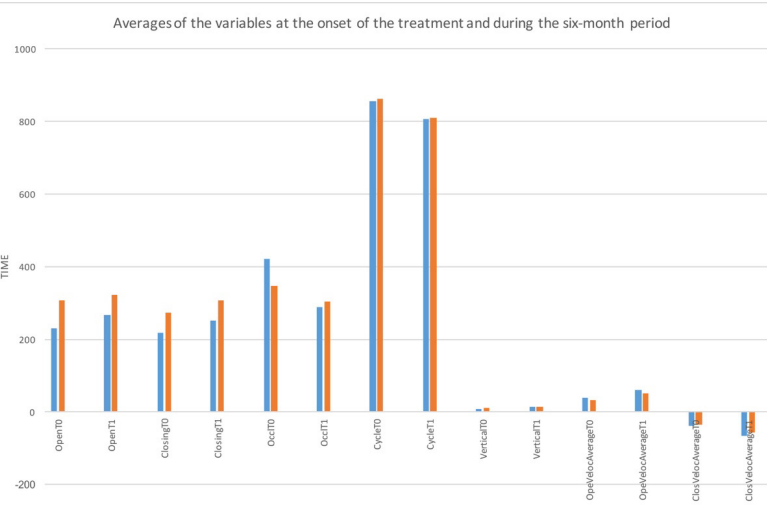

Figure 4. The average of the differences between groups of variables

\begin{tabular}{|c|c|c|c|c|c|c|c|c|}
\hline & $n$ & Range & Minimum & Maximum & Mean & & $\begin{array}{l}\text { Standard } \\
\text { deviation }\end{array}$ & Variance \\
\hline & Statistic & Statistic & Statistic & Statistic & Statistic & Statistic & Statistic & Statistic \\
\hline SNADERTO & 43 & 10.3 & 73.00 & 83.3 & 798023.00 & 0.36 & 2.42 & 5.88 \\
\hline SNADERT1 & 43 & 10.70 & 72.9 & 83.6 & 79.75 & 0.38 & 2.52 & 6.35 \\
\hline SNADERTO & 43 & 12.00 & 70.00 & 82.00 & 76.38 & 0.44 & 2.92 & 8.54 \\
\hline SNADERT1 & 43 & 12.00 & 67.00 & 82.00 & 76.73 & 0.45 & 2.98 & 8.92 \\
\hline SNADERTO & 43 & 12.00 & 67.00 & 79.00 & 74.21 & 0.41 & 2.7 & 7.3 \\
\hline SNADERT1 & 43 & 12,00 & 67.00 & 79.00 & 74.47 & 0.43 & 2.83 & 8.04 \\
\hline ANDERTO & 43 & 7.5 & 0.00 & 7.5 & 3.39 & 0.31 & 2.08 & 4.35 \\
\hline ANDERT1 & 43 & 7.7 & 0.00 & 7.7 & 3.03 & 0.3 & 1.97 & 3.92 \\
\hline PROGNBTOmm & 43 & 6,00 & -1.00 & 5.00 & 1.96 & 0.19 & 1.3 & 1.69 \\
\hline PROGNBT1mm & 43 & 26.00 & -1.00 & 25.00 & 2.6 & 0.57 & 3.73 & 13.98 \\
\hline GOGNSNTOder & 43 & 24.00 & 20.00 & 44.00 & 33.33 & 0.76 & 5.03 & 25.35 \\
\hline GOGNSNT1der & 43 & 22.4 & 21.6 & 44.00 & 33.49 & 0.8 & 5.24 & 27.53 \\
\hline COATOmm & 43 & 17.00 & 72.00 & 89.00 & 80.41 & 0.56 & 3.69 & 13.63 \\
\hline COAT1mm & 43 & 17.00 & 72.00 & 89.00 & 80.82 & 0.59 & 3.91 & 15.36 \\
\hline ANPERPTOmm & 43 & 12.00 & -7.00 & 5.00 & -0.61 & 0.35 & 2.32 & 5.42 \\
\hline ANPERPT1 $1 \mathrm{~mm}$ & 43 & 12.00 & -7.00 & 5.00 & -0.36 & 0.3 & 2.00 & 4.01 \\
\hline ANSMETOmm & 43 & 25.00 & 51.00 & 76.00 & 61.95 & 0.89 & 5.86 & 34.37 \\
\hline ANSMET1mm & 43 & 24.00 & 52.00 & 76.00 & 62.62 & 0.84 & 5.52 & 30.51 \\
\hline BANPTMTOder & 43 & 15.00 & 79.00 & 94.00 & 86.76 & 0.63 & 4.13 & 17.13 \\
\hline BANPTMT1der & 43 & 13.00 & 80.00 & 93.00 & 86.75 & 0.57 & 3.79 & 14.37 \\
\hline SPpgoMeTOder & 43 & 22.00 & 14.00 & 36.00 & 24.2 & 0.72 & 4.77 & 22.78 \\
\hline
\end{tabular}


Table 4. contiuned

\begin{tabular}{|c|c|c|c|c|c|c|c|c|}
\hline SPpgoMeT1der & 43 & 23.00 & 13.00 & 36.00 & 24.72 & 0.72 & 4.72 & 22.3 \\
\hline PNPOGTOmm & 43 & 21.00 & -17.00 & 4.00 & -5.74 & 0.59 & 3.88 & 15.1 \\
\hline PNPOGT1mm & 43 & 20.00 & -16.00 & 4.00 & -5.24 & 0.54 & 3.57 & 12.8 \\
\hline WittsTOmm & 43 & 12.00 & -3.00 & 9.00 & 1.23 & 0.41 & 2.72 & 7.42 \\
\hline WittsT1mm & 43 & 11.00 & -3.00 & 8.00 & 0.87 & 0.4 & 2.63 & 6.95 \\
\hline NA1TOmm & 43 & 17.00 & 0.00 & 17.00 & 5.08 & 0.45 & 2.95 & 8.76 \\
\hline $\mathrm{NA1T} 1 \mathrm{~mm}$ & 43 & 17.00 & 0.00 & 17.00 & 5.11 & 0.41 & 2.74 & 7.52 \\
\hline NA1TODRCE & 43 & 33.00 & 6.00 & 39.00 & 22.63 & 1.16 & 7.66 & 58.69 \\
\hline NA1T1DRCE & 43 & 26.00 & 13.00 & 39.00 & 23.52 & 0.79 & 5.21 & 27.14 \\
\hline NB1TOmm & 43 & 9.00 & 0.00 & 9.00 & 4.43 & 0.31 & 2.02 & 4.1 \\
\hline $\mathrm{NB} 1 \mathrm{~T} 1 \mathrm{~mm}$ & 43 & 9.00 & 0.00 & 9.00 & 4.86 & 0.28 & 1.87 & 3.49 \\
\hline NB1TODRCE & 43 & 23.5 & 11.5 & 35.00 & 24.74 & 0.84 & 5.5 & 3.02 \\
\hline NB1T1DRCE & 43 & 17.3 & 15.7 & 33.00 & 25.69 & 0.66 & 4.29 & 18.46 \\
\hline T011DRCE & 43 & 53.5 & 106.5 & 160.00 & 130.88 & 1.83 & 11.99 & 143.85 \\
\hline T111DRCE & 43 & 52.5 & 107.5 & 160.00 & 129.35 & 1.32 & 8.64 & 74.58 \\
\hline ALT1APGT0mm & 43 & 11.00 & -3.00 & 8.00 & 1.69 & 0.3 & 1.98 & 3.93 \\
\hline ALT1APGT1mm & 43 & 10.00 & -2.00 & 8.00 & 2.04 & 0.29 & 1.91 & 3.66 \\
\hline U1AVERTTOmm & 43 & 17.00 & -5.00 & 12.00 & 3.62 & 0.53 & 3.51 & 12.38 \\
\hline U1AVERTT1mm & 43 & 14.5 & -3.00 & 11.5 & 3.91 & 0.44 & 2.88 & 8.33 \\
\hline OCCLSNTO & 43 & 13.00 & 11.00 & 24.00 & 16.96 & 0.44 & 2.94 & 8.69 \\
\hline OCCLSNT1 & 43 & 23.00 & 2.5 & 25.8 & 16.53 & 0.57 & 3.75 & 14.07 \\
\hline IMPATODRCE & 43 & 35.00 & 74.00 & 109.00 & 92.32 & 1.11 & 7.29 & 53.27 \\
\hline IMPAT1DRCE & 43 & 36.5 & 74.5 & 111.00 & 93.2 & 1,00 & 6.6 & 43.58 \\
\hline HIdawayfarkT0 & 43 & 10.00 & -2.00 & 8.00 & 2.75 & 0.36 & 2.38 & 5.67 \\
\hline HldawayfarkT1 & 43 & 9.00 & -1.00 & 8.00 & 3.02 & 0.35 & 2.33 & 5.46 \\
\hline S-LTO & 43 & 21.00 & 34.00 & 55.00 & 45.46 & 0.67 & 4.43 & 19.68 \\
\hline S-LT1 & 43 & 22.00 & 34.00 & 56.00 & 45.83 & 0.73 & 4.81 & 23.17 \\
\hline S-ETO & 43 & 8.00 & 15.00 & 23.00 & 19.32 & 0.3 & 1.98 & 3.93 \\
\hline S-ET1 & 43 & 7.5 & 15.00 & 22.5 & 19.31 & 0.27 & 1.82 & 3.34 \\
\hline OVERJETTO & 43 & 9.00 & 1.00 & 10.00 & 4.01 & 0.32 & 2.12 & 4.5 \\
\hline OVERJETT1 & 43 & 6.6 & 0.4 & 7.00 & 3.38 & 0.26 & 1.73 & 2.99 \\
\hline OVERBITETO & 43 & 10.5 & -2.5 & 8.00 & 2.68 & 0.34 & 2.28 & 5.21 \\
\hline OVERBITET1 & 43 & 9.9 & -2.9 & 7.00 & 2.45 & 0.28 & 1.89 & 3.6 \\
\hline 6U6LOCPTO & 43 & 8.00 & -3.00 & 5.00 & -0.43 & 0.24 & 1.57 & 2.47 \\
\hline 6U6LOCPT1 & 43 & 8.6 & -3.6 & 5.00 & -0.34 & 0.26 & 1.71 & 2.94 \\
\hline 3U3LOCPT0 & 43 & 8.6 & -3.6 & 5.00 & 0.2 & 0.25 & 1.68 & 2.83 \\
\hline 3U3LOCPT1 & 43 & 8.2 & -3.2 & 5.00 & 0.59 & 0.27 & 1.79 & 3.23 \\
\hline ALT1-OCPT0 & 43 & 6.1 & -0.4 & 5.7 & 2,00 & 0.21 & 1.42 & 2.02 \\
\hline ALT1-OCPT1 & 42 & 5.00 & 0.00 & 5.00 & 1.71 & 0.2 & 1.32 & 1.75 \\
\hline Valid N (listwise) & 42 & & & & & & & \\
\hline
\end{tabular}




\section{Discussion}

The chewing material used in the present study was the chewing gum. The quantity of the gum is equal at each chewing time and the hard gum is softened after 3 to 5 chewing cycles. All participants' chewing movements were recorded when the gum was hard and softened. The chewing patterns obtained in the control group of the present study was found consistent with those obtained by Kuwahara et al. $(12,18)$. Furthermore, such data are quite similar when compared with the findings obtained by both Hill and Piancino et al. $(2,21)$. Since the first 2 or 3 cycles of chewing were not recorded in the present study, this allowed the participants to adopt the equipment used. The results obtained by Papa Ibrahima Ngom et al. (15) are similar with the present study and harmonization of all organs in the chewing system was achieved.

A study conducted by Winocur et al. (22) evaluated the changes in the muscles after orthodontic treatments through the parameters of maximum biting strength, maximum sliding from intercuspal position and muscle sensitivity by palpation; and it was reported that neuromuscular modification just starts in orthodontic treatments and muscle adoptation is observed to be settled within 3-months after the treatment. Similarly, harmonization of opening and closing movements within first 6 -months of the treatment is detected.

This necessary event for harmonization of neuromuscular mechanism was performed in a similar environment mentioned in Schindler's study (8). Comparison of opening and closing velocities between the occlusion group and the control group was used as an indicator for evaluation of chewing efficiency. The closing velocity of the present research was considered as the most important indicator of chewing technique as specified in the study of Radke. Radke reported in his study through use of JT that the velocity ratio in chewing velocity test is an important factor for evaluation of chewing efficiency (23).

Findings of the first phase in the present study are values of the control group as well as initial values of the treatment group. The significant difference between opening and CT fort the control group presented in table 1 is expected; the opening value of the individuals with malocclusion was $271.08 \mathrm{msec}$ and this was very high in the control group as 338.19 msec. The difference between OpenT0 and OpenT1 was found significant in both groups $(p<0.01)$. The difference between CTO and CT1 was $56.763 \mathrm{msec}$ which is significant $(p<0.01)$. Opening period of the control group is $67 \mathrm{msec}$ longer than OT of the malocclusion group. This significant difference is not an unexpected case for pre-treatment period. Higher value and significance of the difference are similar with findings of Lepley et al. (24) and Owens et al. (25). In a comparative study on chewing efficiency conducted by Lepley et al. (24), an artifical Cuttersil chewing material was chown by 30 individuals with class 1 occlusion and chewing performances were compared; they found the OT of the individuals without malocclusion as $274 \pm 22$. When they evaluated with chewing efficiency, such time was detected to increase up to $325 \pm 27 \mathrm{msec}$ in the individuals with malocclusion included into the poor chewing group and detected this difference as significant. The initial opening durations (338.20 $\mathrm{msec}$ ) obtained in the present study are closely similar to durations of the individuals with malocclusion obtained in the study of J. Lepley (24). This indicated that chewing efficiency of the malocclusion group is lower and they have a less efficient chewing performance because of higher values than the control group. However, the difference between occlusion duration parameters in both groups was not significant; this result was considered that the malocclusion group acted faster and had a near-normal chewing pattern during closure. Total cycle time which was not significant at initial values is considered as a poor chewing pattern with a lower chewing performance. The most important parameters showing the chewing efficiency directly are Opening and Closing strength values and confirm this idea. Such results indicate that malocclusion group has a less chewing efficiency when compared with the control group. Values of the chewing efficiency increased due to some causes such as onset of the treatment for malocclusion, accurate movement of the teeth and resolvement of the crowding; in other words, malocclusion group showed a poor chewing efficiency. These findings may be seen in the values at months 6 of orthodontic treatment in Table 2. Since the occlusion started to improve, chewing opening and CT increased $34.54 \mathrm{msec}$ than initial times and the difference was significant $(p<0.05)$. Another important 
effect of the treatment appeared on occlusion times; the initial value of Occlusion Contact Time was $384.07 \mathrm{msec}$ and reduced to $312.44 \mathrm{msec}(\mathrm{p}<0.05)$. The most significant change at months 6 from onset of the treatment was increase of chewing efficiency (Initial value of Op-Velocity) which was 34.54 at the beginning to 54.13 (months 6 value of Op-Velocity) $(p<0.01)$. This reveals the realistic change effect of the treatment on chewing efficiency.

Along with the increase in chewing efficiency in treated individuals, decrease in occlusal contact time indicates that a less time than before may be sufficient even occlusal contact zones were not changes. Occlusion time decreased and the OcclTO value which has an initial value of $384.07 \mathrm{msec}$ reduced to 312.44 msec $(p<0.05)$. Functional occlusal zone was reported to have a more efficient chewing performance than the occlusal surface or plane surface. These findings comply with the outcomes of the studies conducted by Yawaka et al. (26), Owens et al. (25) and Okiyama et al. (27). The evaluation of the chewing movements of the individuals with class 1 and class 2 malocclusions whose growth and development were about to end at $6^{\text {th }}$ month of the treatment suggested a statistically significant imporvement in the values obtained in both groups from onset of the treatment. Open-Velo TO-T1 values demonstrates the changes in initial and 6-months treatment values for class 2 are significant $(p<0.01)$. However, the change rate in the group with class 2 malocclusion is more than the change rate of 25 individuals with class 1 malocclusion. Although such values are concrete, relative values obtained during comparison between them should not be evaluated as unexpected.

\section{Conclusion}

We observed the changes on chewing movements of the individuals with malocclusion whose growth and development are completed within such a short period of 6-months from onset of the treatment when compared with initial values as well as the individuals with normal closing. Such changes are dependent to the treatment. Although this rapid effect of the treatment is considered to appear by recovery of the occlusion, it may also appear due to disruption of routine chewing pattern with malocclusion which was settled into the memory. This should not be ignored at treatment phases. It is also important for undesired temporomandibular disorders after the treatment. Because, it should be considered that the changing occlusion relation may have a positive effect on TMJ. To monitor these studies at the end of the treatment and during retention period after the treatment would be useful.

\section{Ethics}

Ethics Committee Approval: The study protocol was approved by the Ethics Committee at the İstanbul Aydın University, Faculty of Dentistry.

Informed Consent: Written informed consent was obtained from all subjects prior to the study.

Peer-review: Externally peer-reviewed.

Conflict of Interest: There is no conflict of interest of this study.

Financial Support: This project was supported by İstanbul Aydın University as Scientific Research Project.

\section{References}

1. Thomas GP, Throckmorton GS, Ellis E, Sinn DP. The effects of orthodontic treatment on isometric bite forces and mandibular motion in patients before orthognathic surgery. J Oral Maxillofac Surg 1995; 53: 673-8.

2. Hill L. An Introduction to Mastication Analysis in General Practice. Oral Heal Gorup 2016: 1-5.

3. Türker KS, Sowman PF, Tuncer M, Tucker KJ, Brinkworth RSA. The role of periodontal mechanoreceptors in mastication. Arch Oral Biol 2007; 52: 361-4.

4. Slavicek G. Human mastication. Int J Stomatol Occlusion Med 2010; 3: 29-41.

5. Fushima K, Gallo LM, Krebs M, Palla S. Analysis of the TMJ intraarticular space variation: A non-invasive insight during mastication. Med Eng Phys 2003; 25:181-90.

6. Kerstein RB, Radke J. Average chewing pattern improvements following Disclusion Time reduction Average chewing pattern improvements following Disclusion Time reduction. Cranio 2017; 35: 135-51.

7. Abreu M De, Domingues M, Furtado F, Pereira G, Prado R, Mestriner W, et al. ScienceDirect Masticatory efficiency and bite force in individuals with normal occlusion. Arch Oral Biol 2014; 59: 1065-74.

8. Schindler H, Eckehard S, Spiess WEL. Standardization of the registration and analysis of mastication: proposal for clinical application. J Prosthet Dent 2016; 9: 1-7.

9. Da Silva CG, Pachêco-Pereira C, Porporatti AL, Savi MG, Peres MA, Flores-Mir C, et al. Prevalence of clinical signs of intra-articular temporomandibular disorders in children and adolescents $A$ systematic review and meta-analysis. J Am Dent Assoc 2016; 147: 10-18e8. 
10. Kuwahara T, Bessette RW, Maruyama T. Chewing Pattern Analysis in TMD Patients with and without Internal Derangement: Part I. Cranio 1995; 13: 93-8.

11. Ishigaki $S$, Basette $R$, Maruyama $T$. Vibration of the temporomandibular joints with normal radiographic imagings: comparison between asymptomatic volunteers and symptomatic patients. Cranio J Craniomandib Pract 1993; 11: 88-94.

12. Kuwahara T, Miyauchi S, Maruyama T. Clinical classification of the patterns of mandibular movements during mastication in subjects with TMJ disorders. Int J Prosthodont 1993; 5: 122-9.

13. Fushima K, Gallo LM, Krebs M, Palla S. Analysis of the TMJ intraarticular space variation: A non-invasive insight during mastication. Med Eng Phys 2003; 25: 181-90.

14. Trawitzki LV V, Silva JB, Regalo SCH, Mello-Filho F V. Effect of class II and class III dentofacial deformities under orthodontic treatment on maximal isometric bite force. Arch Oral Biol 2011; 56: 972-6.

15. Ngom PI, Diagne F, Aïdara-Tamba AW, Sene A. Relationship between orthodontic anomalies and masticatory function in adults. Am J Orthod Dentofac Orthop 2007; 131: 216-22.

16. Yamashita S, Hatch JP, Rugh JD. Does chewing performance depend upon a specific masticatory pattern? J Oral Rehabil 1999; 26: 547-53.

17. Clark JR, Evans RD. Functional occlusion: I. A review. J Orthod 2001; 28: 76-81.

18. Kuwahara T, Besette R, Maruyama T. Characteristic Chewing Parameters for Specific Types of TMJ Internal Derangements, Kuwahara et al.pdf. Cranio - J Craniomandib Pract 1996; 14: 9086871.
19. Adnan Mazmanoglu. Herkes İçin Temel İstatistik Yöntemleri ve Uygulamaları (Basic Statical Methods and Applications for Everyone). Istanbul: Nobel Kitabevi; 2016.

20. McClave JT, Sincich T. Statistic. 2005th ed. Harvard: Prentice Hall; 2011.

21. Piancino MG, Bracco P, Vallelonga T, Merlo A, Farina D. Effect of bolus hardness on the chewing pattern and activation of masticatory muscles in subjects with normal dental occlusion. J Electromyogr Kinesiol 2008; 18: 931-7.

22. Winocur E, Davidov I, Gazit E, Brosh T, Vardimon AD. Centric Slide, Bite Force and Muscle Tenderness Changes Over 6 Months Following Fixed Orthodontic Treatment. Angle Orthod 2007; 77: 254-9.

23. Radke J. Chewing Pattern Differences Between Subjects Chewing with Different Rates 2015.

24. Lepley CR, Throckmorton GS, Parker S, Buschang PH. Masticatory performance and chewing cycle kinematics- Are they related? Angle Orthod 2010; 80: 295-301.

25. Owens S, Buschang PH, Throckmorton GS, Palmer L, English J. Masticatory performance and areas of occlusal contact and near contact in subjects with normal occlusion and malocclusion. Am J Orthod Dentofac Orthop 2002; 121: 602-9.

26. Yawaka Y, Hironaka S, Akiyama A, Matzuduka I, Takasaki C, Oguchi $\mathrm{H}$. Changes in occlusal contact area and average bite pressure during treatment of anterior crossbite in primary dentition. J Clin Pediatr Dent 2004; 28: 75-9.

27. Okiyama S, Ikebe K, Nokubi T. Association between masticatory performance and maximal occlusal force in young men. J Oral Rehabil 2003; 30: 278-82. 